\title{
Engineering hydration model for ordinary Portland cement based on heat flow calorimetry data
}

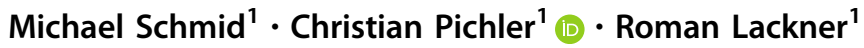

Received: 17 October 2018/Accepted: 28 February 2019/Published online: 9 March 2019

(C) The Author(s) 2019

\begin{abstract}
The reaction kinetic of Portland cement was characterized by heat flow calorimetry, with the experiments conducted at different, constant, curing temperatures. With these data at hand, Ulm and Coussy's classical rate law is extended toward a variable activation energy, reflecting that several sub-reactions take place in parallel/subsequently, what, finally, gives access to an engineering model for hydration kinetics suitable for application in thermochemical analyses of concrete structures at an early age.
\end{abstract}

Keywords Ordinary Portland cement · Hydration kinetics · Modeling

\section{Introduction}

The structural analysis of the early-age mechanical behavior of concrete structures heavily relies on a proper description of the hydration reaction, with degree of hydration $0 \leq \xi \leq 1$ strongly influenced by the temperature history $T(t)$ and vice versa via the second law of thermodynamics [36]. Within the framework introduced by Ulm and Coussy in the early 1990s [36, 37] and successfully employed for the thermochemomechanical analysis of concrete structures at an early age, see, e.g., $[8,9,17-19,28]$, the history of the spatial distribution of the degree of hydration $\xi(\mathbf{x}, t)$ and the temperature $T(\mathbf{x}, t)$ is obtained from a thermochemical analysis of the concrete structure. In the subsequent chemomechanical analysis, giving access to the stress and deformation state of the structure, the evolution of material behavior is described by

Christian Pichler

christian.pichler@uibk.ac.at

Michael Schmid

csak3302@student.uibk.ac.at

Roman Lackner

roman.lackner@uibk.ac.at

1 Christian Doppler Laboratory for Cement and Concrete Technology, Material Technology Innsbruck (MTI), University of Innsbruck, Technikerstraße 13, 6020 Innsbruck, Austria material functions linking parameters (elastic parameters, strength parameters, etc.) to the degree of hydration $\xi$. On the other hand, the temperature history from thermochemical analysis gives access to thermal eigenstrains $\varepsilon^{\text {th }}(\mathbf{x}, t)=\alpha \Delta T(\mathbf{x}, t)$, with $\alpha\left[\mathrm{K}^{-1}\right]$ as the coefficient of thermal dilation. In this paper, we revisit the rate law commonly employed in thermochemical analysis of concrete structures.

Employing a stringent thermodynamics framework, $[36,37]$ introduced a rate law for the degree of hydration $\xi[-]$, where the latter scales linearly to the mass of water bound in hydration products formed (or cement consumed [3]), i.e., initially amounting to zero and reaching one in case all cement in the considered material volume has reacted with water (given the water/cement ratio $w / c$ is large enough). The time derivative of $\xi$ or rate of the degree of hydration is given as

$$
\dot{\xi}(t)=A(\xi(t)) \exp \left(-\frac{E_{\mathrm{a}}}{\mathcal{R} T(t)}\right) .
$$

In Eq. (1), $A(\xi)[1 / \mathrm{s}]$ denotes the so-called chemical affinity of the employed cement, a material function depicting the complex (parallel and/or sequential) hydration reactions in Portland-cement-based material systems, see e.g., [3, 33], which primarily depends on cement composition, grinding fineness, and water/cement ratio $w$ / $c ; E_{\mathrm{a}}\left[\mathrm{J} \mathrm{mol}^{-1}\right]$ denotes the activation energy, $\mathcal{R}=$ $8.314 \mathrm{~J} \mathrm{~mol}^{-1} \mathrm{~K}^{-1}$ is the gas constant. 
In the rate law (1), an increase in temperature $T[\mathrm{~K}]$ results in an increase in the Arrhenius term $\exp \left[-E_{\mathrm{a}} /(\mathcal{R} T)\right]$ and hence in a higher reaction rate. Note further the decoupling hypothesis in Eq. (1), temperature variations do not influence the chemical affinity, i.e., affinity is a function of $\xi$ only, $A=A(\xi)$. In [37], (1) adiabatic calorimetry or (2) isothermal strength gain [assuming a linear relation $\left.f_{\mathrm{c}} / f_{\mathrm{c}, \infty}=\left(\xi-\xi_{0}\right) /\left(1-\xi_{0}\right)\right]$ was employed for the determination of $A(\xi)$. In "Investigated material and calorimetric data" section of this paper, we will employ isothermal calorimetry for the determination of the chemical affinity.

More refined, multiphase, kinetics models, considering the binder composition, e.g., the four clinker phases and gypsum in Portland cement, see, e.g., [3, 24, 25, 27], have been proposed. These models, however, rely heavily on verified material parameters (e.g., rate constants in the scopes of modeling with the Avrami law, which may change with water/cement ratio and grinding fineness) for all clinker phases (and reprocessed product phases, e.g., ettringite and portlandite) and/or separable reactions (e.g., tricalcium aluminate reaction is a multistage reaction in the presence of gypsum). Whereas some of these parameters have been available for some time (e.g., for tricalcium silicate $[2,6,35])$, others are still part of the current research. Furthermore, the bulk of these multiscale models employs kinetic models (Avrami model, i.e., bulk nucleation and growth, diffusion-based Jander model $[6,10]$ ) that have been dismissed in the cement research community in recent years, see, e.g., review papers $[4,32]$. On the other hand, substantial effort has been undertaken in recent years as regards hydration kinetics of tricalcium silicate, the abundant phase in all Portland-cement-based material systems, see, e.g., [4, 32]. These models for tricalcium silicate hydration are complex, there is an ongoing debate on the underlying rate-controlling mechanisms (and competing modeling frameworks), models for the interaction with the other clinker phases in Portland cement are not available yet or still at very early stages of development.

The stated reasons make the macroscopic approach (Ulm and Coussy's thermodynamic approach as described above), relying on, for example, simple calorimetric tests of a certain binder material still attractive as regards an engineering description of hydration in the scopes of thermochemomechanical analysis of early-age concrete structures.

\section{Investigated material and calorimetric data}

We investigated a commercial, properly sulfated Portland cement type CEM I $425 \mathrm{R}$ with mass fractions of the main clinker phases as obtained by XRD-Rietveld analysis summarized in Table 1. In the scopes of the calorimetric experiments (isothermal heat flow calorimeter TONI Cal 6 ), the heat release rate of a hydrating cement sample (related to the mass of cement in the sample) $\dot{Q}\left[\mathrm{~J} \mathrm{~g}^{-1} \mathrm{~h}^{-1}\right]$ was monitored at isothermal conditions, with the experiments conducted at $T=$ const. $=273+22.6=295.6 \mathrm{~K}$, $=273+31.6=304.6 \mathrm{~K}$, and $=273+40.6=313.6 \mathrm{~K}$, respectively (see Fig. 1). The heat release history of the sample, $Q(t)=\int_{0}^{t} \dot{Q}(\tau) \mathrm{d} \tau$, was determined from time integration of the monitored heat release rate $\dot{Q}$ till $\dot{Q}$ drops below $0.5 \mathrm{~J} \mathrm{~g}^{-1} \mathrm{~h}^{-1}$, see Fig. 1c.

The current understanding as regards the parallel hydration/interaction of tricalcium silicate, tricalcium aluminate and sulfate (from gypsum, bassanite or anhydrite) in real-life properly sulfated Portland cement systems can be found in review papers, e.g., $[4,32]$, in $[1,13]$ or $[7,20,21]$, with the latter authors considering different curing temperatures. Several reaction peaks can be observed from calorimetric data:

- The initial reaction (first hour) and associated "dissolution peak" are only marginally influenced by the curing temperature (see Fig. 1a). Upon contact with water, besides the dissolution of $\mathrm{C}_{3} \mathrm{~S}$ releasing a significant amount of heat, tricalcium aluminate and very soluble sulfate carriers (bassanite) dissolve significantly [12] and ettringite precipitates rapidly. Heat flow then declines significantly as tricalcium aluminate dissolution stops or is extremely slow. According to [23], the latter is caused by adsorption of calcium and/ or sulfate ions on the tricalcium aluminate surface. [13] recently concluded that the rapid adsorption of sulfur and aluminum leads to the passivation of tricalcium aluminate.

- A second reaction peak is initiated at $t \approx 2 \mathrm{~h}$, with consensus in the literature that this "silicate peak" is caused by alite dissolution and precipitation of $\mathrm{C}-\mathrm{S}-\mathrm{H}$

Table 1 Mass fractions obtained by XRD-Rietveld analysis of investigated Portland cement CEM I $425 \mathrm{R}$; note that standard cement chemistry abbreviations are used throughout this paper: $\mathrm{C}=\mathrm{CaO}$, $\mathrm{S}=\mathrm{SiO}_{2}, \mathrm{~A}=\mathrm{Al}_{2} \mathrm{O}_{3}, \mathrm{~F}=\mathrm{Fe}_{2} \mathrm{O}_{3}, \overline{\mathrm{S}}=\mathrm{SO}_{3}, \mathrm{H}=\mathrm{H}_{2} \mathrm{O}$

\begin{tabular}{ll}
\hline & Mass fraction/\% \\
\hline $\mathrm{C}_{3} \mathrm{~S}$ monoclinic tricalcium silicate (alite) & 57.0 \\
$\mathrm{C}_{3} \mathrm{~A}$ tricalcium aluminate & 10.5 \\
$\mathrm{C}_{2} \mathrm{~S}$ dicalcium silicate & 12.5 \\
$\mathrm{C}_{4} \mathrm{AF}$ tetracalcium aluminate ferrite & 6.4 \\
$\mathrm{C} \overline{\mathrm{S}} \mathrm{H}_{2}$ gypsum & 4.2 \\
$\mathrm{C} \overline{\mathrm{S}} \mathrm{H}_{1 / 2}$ bassanite & 2.7 \\
$\mathrm{C} \overline{\mathrm{S}}$ anhydrite & 0.2 \\
\hline
\end{tabular}


(a)

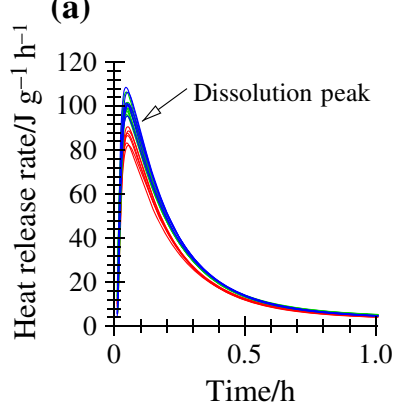

(c)

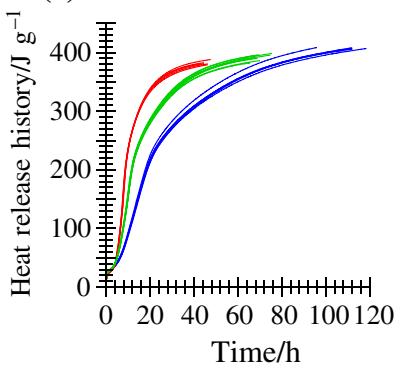

(b)

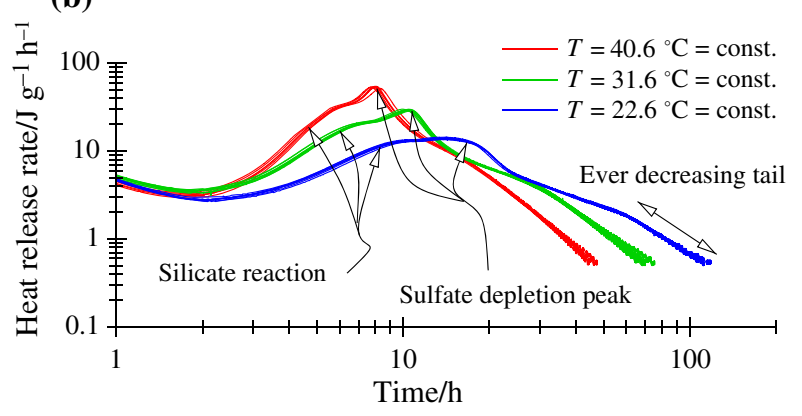

Fig. 1 a and $\mathbf{b}$ heat release rate $\dot{Q}(t)$, $\mathbf{c}$ heat release history $Q(t)$ of ordinary Portland cement samples for different isothermal curing temperatures (multiple re-run of experiments)

and portlandite (silicate reaction, see Fig. 1b) and precipitation of ettringite $[1,11,13]$; there is no consensus on the rate-controlling mechanism. According to [13], the passivation of tricalcium aluminate remains until (dissolved) sulfate is completely consumed by ettringite precipitation occurring continuously until sulfate is depleted, i.e., the amount of $\mathrm{C}_{3} \mathrm{~A}$ dissolved upon contact with water is sufficient to allow for precipitation of ettringite until further dissolution of $\mathrm{C}_{3} \mathrm{~A}$ is observed [11].

- In properly sulfated systems, a third reaction (the socalled shoulder peak) superimposes the second reaction peak (silicate peak). This shoulder peak (as compared to the second reaction peak) is more pronounced for higher curing temperatures (see Fig. 1b). For the mechanisms associated with this "sulfate depletion peak" see $[11,13]$. The sulfate necessary for further formation of ettringite comes from $\mathrm{C}-\mathrm{S}-\mathrm{H}$, where it has previously been absorbed (when sulfate concentration in solution was high) [31]. This sulfate is released back into the solution from $\mathrm{C}-\mathrm{S}-\mathrm{H}$ surfaces. Furthermore, [13] found no relation between adsorbed calcium ions and sulfate depletion (tricalcium aluminate passivation by adsorption of calcium as proposed by [23]). Monosulfate (reaction of tricalcium aluminate and ettringite) only forms later, often not well visible in calorimetric measurement, what seems to be the case in our experiments.
- What follows is a reaction tail characterized by an everdecreasing heat release rate.

In the heat flow calorimeter employed, the heat release rate $\dot{Q}[\mathrm{~J} / \mathrm{h}]$ of the hydrating cement paste sample is monitored for isothermal conditions, $T(t)=$ const. The underlying field equation for the thermochemically coupled problem, the first law of thermodynamics, reads [36]

$(\rho c) \dot{T}-\ell_{\xi} \dot{\xi}=-\nabla \cdot \mathbf{q}$,

with $(\rho c)\left[\mathrm{J} \mathrm{m}^{-3} \mathrm{~K}^{-1}\right]$ as the volume heat capacity, $\ell_{\xi}\left[\mathrm{J} \mathrm{m}^{-3}\right]$ as the specific latent heat of the hydration process and $\mathbf{q}\left[\mathrm{J} \mathrm{m}^{-2} \mathrm{~h}^{-1}\right]$ as the heat flow vector. Specializing Eq. (2) for isothermal conditions, $T=$ const. $\rightarrow \dot{T}=\partial T / \partial t=0$, and integration over the sample volume $V$ (underlying a spatially uniform degree of hydration in the sample) gives

$\dot{\xi}_{\ell_{\xi}} V=\int_{V} \nabla \cdot \mathbf{q} \mathrm{d} V$

Denoting $Q_{\infty}=\ell_{\xi} V$ as the latent heat of the sample [J] and applying the divergence theorem to the right-hand side of Eq. (3), with

$\int_{V} \nabla \cdot \mathbf{q} \mathrm{d} V=\oint_{S} \mathbf{q} \cdot \mathbf{n} \mathrm{d} S$

gives

$\dot{\xi} Q_{\infty}=\oint_{S} \mathbf{q} \cdot \mathbf{n} \mathrm{d} S$.

With the heat flow through the sample surface $S$ being measured, $\dot{Q}=\oint_{S} \mathbf{q} \cdot \mathbf{n} \mathrm{d} S$, Eq. (5) gives

$\dot{\xi}=\frac{\dot{Q}}{Q_{\infty}}$.

Note that in this paper $\dot{Q}$ and $Q_{\infty}$ are scaled by the mass of cement in the paste sample.

\section{Classical way for determination of chemical affinity}

Specializing Eq. (1) for isothermal conditions, i.e., $T=$ const., and using Eq. (6) give access to $A(\xi)$ of the investigated cement sample as (see Fig. 2) 

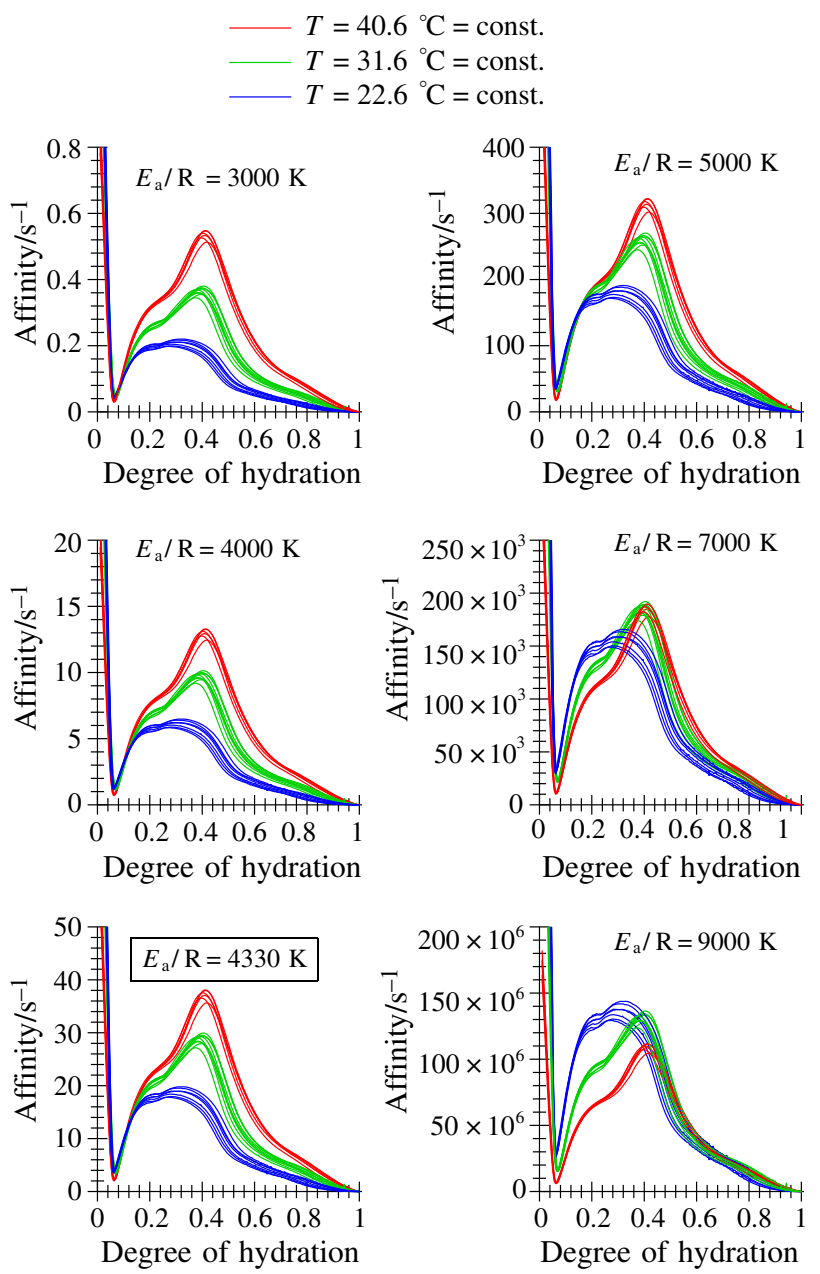

Fig. 2 Back-calculated affinity $A(\xi)$ for different prescribed values of $E_{\mathrm{a}} / \mathcal{R}$ where $E_{\mathrm{a}} / \mathcal{R}=4330 \mathrm{~K}$ corresponds to $E_{\mathrm{a}}=36 \mathrm{~kJ} \mathrm{~mol}^{-1}$, the value determined for the apparent activation energy of Portland cement in [34]

$$
\begin{array}{r}
\dot{\xi}=A[\xi(t)] \exp \left(-\frac{E_{\mathrm{a}}}{\mathcal{R} T}\right)=\frac{\dot{Q}(t)}{Q_{\infty}} \rightarrow \\
\rightarrow \quad A[\xi(t)]=\frac{\dot{Q}(t)}{Q_{\infty}} \frac{1}{\exp \left(-\frac{E_{\mathrm{a}}}{\mathcal{R} T}\right)} \\
\text { with } \xi(t)=\frac{\int_{0}^{t} \dot{Q}(\tau) \mathrm{d} \tau}{Q_{\infty}}=\frac{Q}{Q_{\infty}} .
\end{array}
$$

The latent heat (or overall heat release) $Q_{\infty}\left[\mathrm{J} \mathrm{g}^{-1}\right]$ was determined by approximating the tail of the heat release rate history with a reaction-order model ansatz, as detailed and justified in [26]: Denoting the concentration of the transformed substance as $c$, the rate law for an $n$th order reaction is given as $-\mathrm{d} c / \mathrm{d} t=k c^{\mathrm{n}}$ with rate constant $k$ $\left[\mathrm{h}^{-1}\right]$ and reaction order $n[-]$. Replacing $c$ (what in our case is the concentration of unreacted Portland cement in the material system) by $(1-\xi)$ gives $-\frac{\mathrm{d}}{\mathrm{d} t}(1-\xi)=\dot{\xi}$, hence

$\dot{\xi}=k(1-\xi)^{\mathrm{n}}$.

Using the change of variables, $\dot{\xi}(t) \rightarrow \dot{Q}(t)$ and $\xi(t) \rightarrow Q(t)$, as previously described, in Eq. (8), the fitting function reads

$\dot{Q}=k Q_{\infty}\left(1-\frac{Q}{Q_{\infty}}\right)^{\mathrm{n}}$

with parameters $k, n$ and $Q_{\infty}$ determined by the Levenberg-Marquardt algorithm [22, 30] and depicted in an Arrhenius diagram in Fig. 3, where the reduction of the overall heat release $Q_{\infty}$ with increasing curing temperature is consistent with the previous results in the literature $[14,16]$.

Let us try to assess whether the separation in Eq. (1) into a temperature-dependent part (Arrhenius term) and reaction-extent-dependent part [affinity function $A(\xi)$ ] is justified. Figure 2 shows the obtained affinity functions for various prescribed activation energies. Note that a collapse into a single master curve is not possible. Only (different) parts of the affinity function collapse for certain prescribed activation energies, with $E_{\mathrm{a}} / \mathcal{R}=4330 \mathrm{~K}$ (related to the apparent activation energy of $36 \mathrm{~kJ} \mathrm{~mol}^{-1}$ as determined by [34]) achieving the collapse for the increasing slope of the silicate reaction (see Fig. 2). The sulfate depletion peak

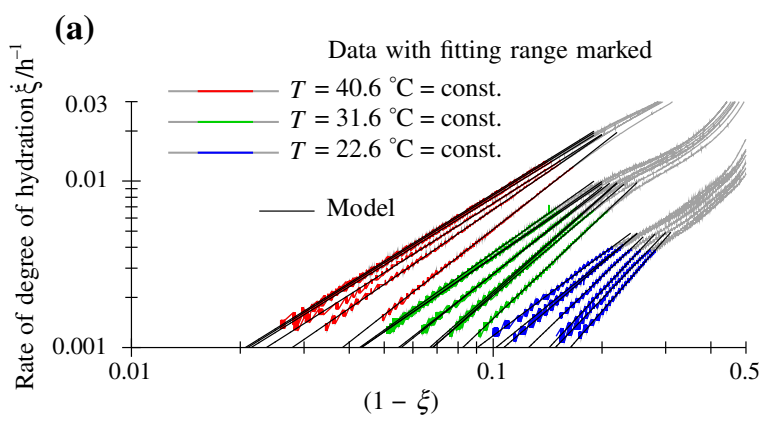

(b)

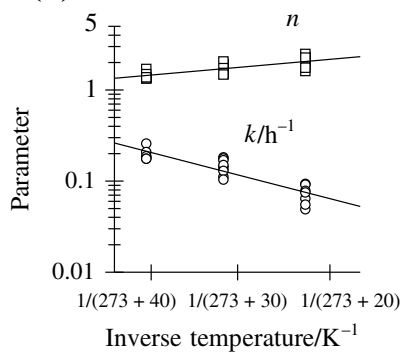

(c)

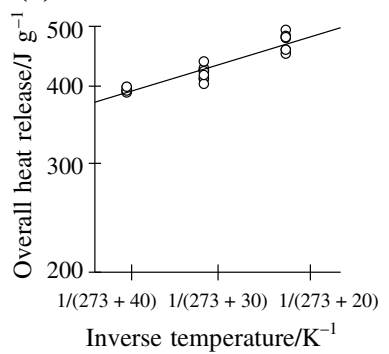

Fig. 3 a Good fit of reaction-order modeling illustrated by linearization of tail data in double logarithmic diagram $\dot{\xi}$ versus $(1-\xi)$; Arrhenius plot of parameters, $\mathbf{b} k, n$, and $\mathbf{c}$ overall heat release $Q_{\infty}$ of reaction-order model 
superimposes the silicate reaction. Much higher values for $E_{\mathrm{a}} / \mathcal{R}$ are necessary to collapse the increasing/decreasing slope of the sulfate depletion peak (r.h.s. of Fig. 2).

\section{Alternative formulation and determination of chemical affinity}

Based on the result shown in Fig. 2, one may conclude that a single apparent activation energy is not capable for depicting the parallel/subsequent reactions in real-life Portland-cement-based material systems, as all these reactions may be attributed by substantially different activation energies. A viable approach may consist of making the activation energy dependent on the reaction extent $E_{\mathrm{a}}=E_{\mathrm{a}}(\xi)$ (compare to the previous work, e.g., $[5,15,29])$. Hence, we modify Ulm and Coussy's rate law toward

$$
\begin{array}{r}
\dot{\xi}(\xi, T)=A\left(\xi, T_{\text {ref }}\right) \exp \left(-\frac{E_{\mathrm{a}}(\xi)}{\mathcal{R}}\left(\frac{1}{T}-\frac{1}{T_{\text {ref }}}\right)\right) \\
\text { with } \quad A\left(\xi, T_{\text {ref }}\right)=\dot{\xi}\left(\xi, T=T_{\text {ref }}\right)
\end{array}
$$

and $T_{\text {ref }}=273+30=303 \mathrm{~K}$ denoting an arbitrarily chosen reference temperature. Rewriting Eq. (10) as

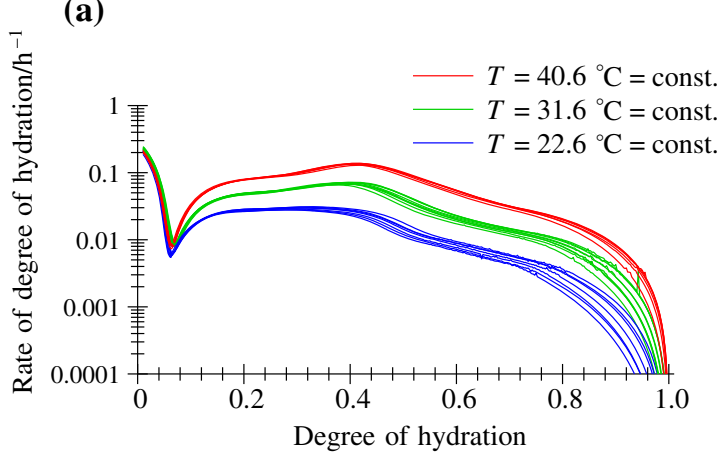

(b)

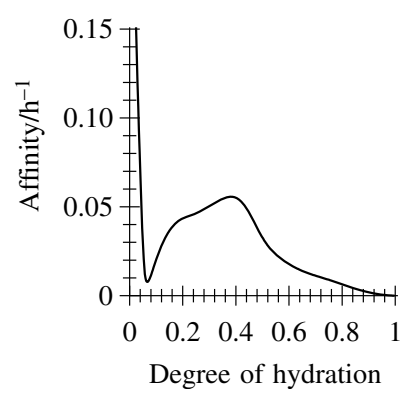

(c)

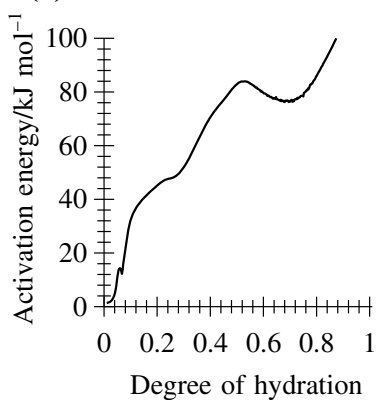

Fig. 4 a Data, $\dot{\xi}=\dot{Q} / Q_{\infty}$ versus $\xi=Q / Q_{\infty}$, employed for determination of material functions, $\mathbf{b}$ affinity $A\left(\xi, T_{\text {ref }}=303 \mathrm{~K}\right)$ and $\mathbf{c}$ activation energy $E_{\mathrm{a}}$ in reformulated rate law $-\ln \dot{\xi}(\xi, T)=-\ln \dot{\xi}\left(\xi, T=T_{\text {ref }}\right)+\frac{E_{\mathrm{a}}(\xi)}{\mathcal{R}}\left(\frac{1}{T}-\frac{1}{T_{\text {ref }}}\right)$

and performing a linear fit of $-\ln \dot{\xi}(\xi, T)$ versus $(1 / T-$ $\left.1 / T_{\text {ref }}\right) / \mathcal{R}$ data for a certain value of $\xi$ gives access to $A(\xi)=\dot{\xi}\left(\xi, T=T_{\text {ref }}\right)$ and $E_{\mathrm{a}}(\xi)$, see Fig. 4 .

\section{Concluding remarks}

In this paper, we revisited Ulm and Coussy's classical rate law for the description of hydration kinetics of Portlandcement-based material systems. For this purpose, data obtained from heat flow calorimetry conducted at different (constant) temperatures cannot be merged into a unique affinity function. This is due to the fact that several subreactions take place in parallel and/or subsequently in reallife material systems, with these different sub-reactions characterized by various activation energies. In order to reflect the latter, we suggested a modification of the classical rate law. This approach seems viable for determination of (1) temperature history in the scopes of thermochemical analyses and (2) thermal eigenstrains in the scopes of chemomechanical analyses of early-age concrete structures, respectively.

We are currently working on material functions linking the evolution of mechanical material parameters to the degree of hydration/degree of reaction. However, linking the strength/stiffness evolution to $\xi$ as defined in this paper is not satisfactorily. Rather than considering the overall reaction, one has to filter out the strength/stiffness determining sub-reaction in calorimetric data (i.e., silicate reaction in Fig. 1b) in order to determine a reaction degree $X$ governing the evolution of mechanical material properties.

Acknowledgements Open access funding provided by University of Innsbruck and Medical University of Innsbruck. Financial support by the Christian Doppler Gesellschaft (Vienna, Austria) is gratefully acknowledged.

Open Access This article is distributed under the terms of the Creative Commons Attribution 4.0 International License (http://creative commons.org/licenses/by/4.0/), which permits unrestricted use, distribution, and reproduction in any medium, provided you give appropriate credit to the original author(s) and the source, provide a link to the Creative Commons license, and indicate if changes were made.

\section{References}

1. Bergold ST, Goetz-Neunhoeffer F, Neubauer J. Interaction of silicate and aluminate reaction in a synthetic cement system: 
implications for the process of alite hydration. Cem Concr Res. 2017;93:32-44.

2. Berliner R, Popovici M, Herwig KW, Berliner M, Jennings HM, Thomas J. Quasielastic neutron scattering study of the effect of water-to-cement ratio on the hydration kinetics of tricalcium silicate. Cem Concr Res. 1998;28(2):231-43.

3. Bernard O, Ulm FJ, Lemarchand E. A multiscale micromechanics-hydration model for the early-age elastic properties of cement-based materials. Cem Concr Res. 2003;33:1293-309.

4. Bullard JW, Jennings HM, Livingston RA, Nonat A, Scherer GW, Schweitzer JS, Scrivener KL, Thomas JJ. Mechanisms of cement hydration. Cem Concr Res. 2011;41(12):1208-23.

5. D'Aloia L, Chanvillard G. Determining the "apparent" activation energy of concrete $E_{a}$-numerical simulations of the heat of hydration of cement. Cem Concr Res. 2002;32:1277-89.

6. Fuji K, Kondo W. Kinetics of the hydration of tricalcium silicate. J Am Ceram Soc. 1974;57:492-502.

7. Han F, Zhang Z. Hydration, mechanical properties and durability of high-strength concrete under different curing conditions. J Therm Anal Calorim. 2018;132(2):823-34. https://doi.org/10. 1007/s10973-018-7007-3.

8. Hellmich C, Ulm FJ, Mang HA. Multisurface chemoplasticity. I: material model for shotcrete. J Eng Mech (ASCE). 1999;125(6):692-701.

9. Hellmich C, Ulm FJ, Mang HA. Multisurface chemoplasticity. II: numerical studies on NATM tunneling. J Eng Mech (ASCE). 1999;125(6):702-13.

10. Jander W. Reaktionen im festen Zustande bei höheren Temperaturen [Kinetic model for solid-state reactions]. Zeitschrift für anorganische und allgemeine Chemie. 1927;163:1-30.

11. Jansen D, Goetz-Neunhoeffer F, Lothenbach B, Neubauer J. The early hydration of Ordinary Portland Cement (OPC): an approach comparing measured heat flow with calculated heat flow from QXRD. Cem Concr Res. 2012;42(1):134-8.

12. Jansen D, Goetz-Neunhoeffer F, Stabler C, Neubauer J. A remastered external standard method applied to the quantification of early OPC hydration. Cem Concr Res. 2011;41(6):602-8.

13. Jansen D, Naber C, Ectors D, Lu Z, Kong XM, Goetz-Neunhoeffer F, Neubauer J. The early hydration of OPC investigated by in-situ XRD, heat flow calorimetry, pore water analysis and $1 \mathrm{H}$ NMR: learning about adsorbed ions from a complete mass balance approach. Cem Concr Res. 2018;109:230-42.

14. Joseph S, Bishnoi S, Van Balen K, Cizer Ö. Effect of the densification of $\mathrm{CSH}$ on hydration kinetics of tricalcium silicate. J Am Ceram Soc. 2018;101:2438-49.

15. Kada-Benameur H, Wirquin E, Duthoit B. Determination of apparent activation energy of concrete by isothermal calorimetry. Cem Concr Res. 2000;30(2):301-5.

16. Kjellsen KO, Detwiller RJ. Reaction kinetics of Portland cement mortars hydrated at different temperatures. Cem Concr Res. 1992;22:112-20.

17. Lackner R, Hellmich C, Mang HA. Constitutive modeling of cementitious materials in the framework of chemoplasticity. Int $\mathbf{J}$ Numer Methods Eng. 2002;53(10):2357-88.

18. Lackner R, Mang HA. Cracking in shotcrete tunnel shells. Eng Fract Mech. 2003;70:1047-68.

19. Lackner R, Mang HA. Chemoplastic material model for the simulation of early-age cracking: from the constitutive law to numerical analyses of massive concrete structures. Cem Concr Compos. 2004;26(5):551-62.

20. Li C, Lu X, Jing G, Ye Z, Wang S, Cheng X. The effect of gypsum on the hydration of alite-belite-ferrite phase system. J Therm Anal Calorim. 2018; https://doi.org/10.1007/s10973018-7643-7.

21. Maciel MH, Soares GS, de Oliveira Romano RC, Cincotto MA. Monitoring of Portland cement chemical reaction and quantification of the hydrated products by XRD and TG in function of the stoppage hydration technique. J Therm Anal Calorim. 2018; https://doi.org/10.1007/s10973-018-7734-5.

22. Marquardt DW. An algorithm for least-squares estimation of nonlinear parameters. J Soc Ind Appl Math. 1963;11(2):431-41.

23. Minard H, Garrault S, Regnaud L, Nonat A. Mechanisms and parameters controlling the tricalcium aluminate reactivity in the presence of gypsum. Cem Concr Res. 2007;37(10):1418-26.

24. Pang X, Meyer C. Modeling cement hydration by connecting a nucleation and growth mechanism with a diffusion mechanism. Part I: C3S hydration in dilute suspensions. Sci Eng Compos Mater. 2016;23(3):345-56.

25. Pang X, Meyer C. Modeling cement hydration by connecting a nucleation and growth mechanism with a diffusion mechanism. Part II: Portland cement paste hydration. Sci Eng Compos Mater. 2016;23(6):605-15.

26. Pichler C, Lackner R. Post-peak deceleration reaction of Portland cement: monitoring by heat flow calorimetry, modelling by Elovich-Landsberg model and reaction-order model. Cem Concr Res. 2019 (Submitted for publication).

27. Pichler C, Lackner R, Mang HA. A multiscale micromechanics model for the autogenous-shrinkage deformation of early-age cement-based materials. Eng Fract Mech. 2007;74(1-2):34-58.

28. Pichler C, Lackner R, Spira Y, Mang HA. Thermochemomechanical assessment of ground improvement by jet grouting in tunneling. J Eng Mech (ASCE). 2003;129(8):951-62.

29. Poole JL, Riding KA, Folliard KJ, Juenger MCG, Schindler AK. Methods for calculating activation energy for Portland cement. ACI Mater J. 2007;104(1):303-11. https://doi.org/10.14359/ 18499.

30. Press HP, Flannery BP, Teukolsky SA, Vetterling WT. Numerical recipes in Fortran 77: the art of scientific computing. 2nd ed. Cambridge: Cambridge University Press; 1992.

31. Quennoz A, Scrivener KL. Interactions between alite and C3Agypsum hydrations in model cements. Cem Concr Res. 2013;44:46-54.

32. Scrivener KL, Juilland P, Monteiro PJM. Advances in understanding hydration of Portland cement. Keynote papers from 14th international congress on the chemistry of cement (ICCC 2015). Cement and Concrete Research, vol. 78(Part A), pp. 38-56 (2015).

33. Tennis PD, Jennings HM. A model for two types of calcium silicate hydrate in the microstructure of Portland cement pastes. Cem Concr Res. 2000;30:855-63.

34. Termkhajornkit P, Barbarulo R. Modeling the coupled effects of temperature and fineness of Portland cement on the hydration kinetics in cement paste. Cem Concr Res. 2012;42(3):526-38.

35. Thomas JJ, Jennings HM. Effects of D2O and mixing on the early-age hydration kinetics of tricalcium silicate. Chem Mater. 1999;11:1907-14.

36. Ulm FJ, Coussy O. Modeling of thermochemomechanical couplings of concrete at early ages. J Eng Mech (ASCE). 1995;121(7):785-94.

37. Ulm FJ, Coussy O. Strength growth as chemo-plastic hardening in early age concrete. J Eng Mech (ASCE). 1996;122(12):1123-32.

Publisher's Note Springer Nature remains neutral with regard to jurisdictional claims in published maps and institutional affiliations. 